\title{
Uma Webquest para promover a Aprendizagem Significativa no ensino de Isomeria
}

\section{Óptica}

\author{
A Webquest to promote Significant Learning in Optical Isomery teaching \\ Una Webquest para promover un Aprendizaje Significativo en la enseñanza de Isomerías Ópticas
}

Recebido: 18/06/2021 | Revisado: 25/06/2021 | Aceito: 28/06/2021 | Publicado: 13/07/2021

\author{
Alanis Luckwu da Silva \\ ORCID: https://orcid.org/0000-0002-8281-5814 \\ Universidade Católica de Pernambuco, Brasil \\ E-mail: alanis.luckwu1@gmail.com \\ Liderlânio Almeida de Araújo \\ ORCID: https://orcid.org/0000-0002-4081-4354 \\ Universidade Federal de Pernambuco, Brasil \\ E-mail: liderlanioalmeida@gmail.com \\ Lúcia Fernanda Cavalcanti da Costa Leite \\ ORCID: https://orcid.org/0000-0001-6581-1275 \\ Universidade Católica de Pernambuco, Brasil \\ E-mail: 1fernanda100@gmail.com
}

\begin{abstract}
Resumo
No século XXI é notório o quanto os adolescentes sabem manusear dispositivos digitais, como smartphones e tablets, isso revela a importância da inserção dessas tecnologias na educação. Uma vez que os smartphones são como uma extensão do corpo desses jovens, ao torná-los um recurso didático é despertado interesse nos estudantes. O presente estudo, visou abordar o conteúdo Isomeria Óptica, um tema da química atribuído pelos estudantes como não importante, através da ferramenta Webquest que buscou despertar o interesse dos educandos de uma turma de terceiro ano do ensino médio, para melhor aplicação da pesquisa a turma foi dividida em 5 grupos. Durante o desenvolvimento da atividade, cada grupo teve a tarefa de fazer um desenho 3D num cartaz sobre o tema designado pela professora-pesquisadora, e depois apresentar o tema representado pelos desenhos do cartaz. Com a presente pesquisa, constatou-se a maior interação e participação dos estudantes, como também a construção de algumas competências como: empatia e cooperação, a cultura digital, o domínio do conteúdo, a criatividade e a comunicação.
\end{abstract}

Palavras-chave: Química; Ensino; Webquest; Tecnologia na educação.

\begin{abstract}
In the 21 st century, it is notorious how much teenagers know how to handle digital devices, such as smartphones and tablets, which reveals the importance of including these technologies in education. Since smartphones are like an extension of the bodies of these young people, by turning them into a didactic resource, students' interest is aroused. The present study aimed to address the Isomeria Óptica content, a chemistry theme attributed by students as not important, through the Webquest tool that sought to arouse the interest of students from a third-year high school class, for better application of the research to the class. was divided into 5 groups. During the development of the activity, each group had the task of drawing a 3D drawing on a poster about the theme designated by the teacher-researcher, and then presenting the theme represented by the drawings on the poster. With this research, it was found a greater interaction and participation of students, as well as the construction of some skills such as: empathy and cooperation, digital culture, mastery of content, creativity and communication.
\end{abstract}

Keywords: Chemistry; Teaching; Webquest; Technology in education.

\section{Resumen}

En el siglo XXI, es notorio cuánto saben los adolescentes cómo manejar dispositivos digitales, como teléfonos inteligentes y tabletas, lo que revela la importancia de insertar estas tecnologías en la educación. Dado que los teléfonos inteligentes son como una extensión del cuerpo de estos jóvenes, al convertirlos en un recurso didáctico despierta el interés de los estudiantes. El presente estudio tuvo como objetivo abordar el contenido de Isomeria Óptica, tema de química atribuido por los estudiantes como no importante, a través de la herramienta Webquest que buscaba despertar el interés de los estudiantes de una promoción de tercer año de bachillerato, para una mejor aplicación de la investigación a la La clase se dividió en 5 grupos. Durante el desarrollo de la actividad, cada grupo tuvo la tarea de dibujar un dibujo en 3D en un cartel sobre el tema designado por el docente-investigador, y luego presentar el tema representado por los dibujos en el cartel. Con esta investigación se encontró una mayor interacción y 
participación de los estudiantes, así como la construcción de algunas habilidades como: empatía y cooperación, cultura digital, dominio de contenidos, creatividad y comunicación.

Palabras clave: Química; Enseñando; Webquest; Tecnología en educación.

\section{Introdução}

Com a chegada da era digital (1980), o mundo passou por uma progressiva automatização na criação, nas relações pessoais, na mobilidade, entre outros fatores. O impacto disso na geração atual é muito perceptível quando se observa uma criança com um celular nas mãos, manipulando os recursos até melhor do que um adulto. Da mesma forma, ao ver adolescentes e jovens que aprendem a programar na tentativa e erro, apenas vendo vídeos nas redes sociais, e até criam robôs dentro de casa.

Essa geração de Nativos Digitais, assim nomeada por Palfrey e Gasser (2011), não larga os smartphones, tablets ou computadores até mesmo nas horas de suas refeições, portanto estão sempre atentos aos seus dispositivos digitais. Tendo em vista essa realidade, fica cada vez mais difícil para o professor manter a atenção dos alunos em suas aulas, seja qual for o conteúdo abordado, muitas vezes os alunos acreditam não precisar assistir uma determinada aula, alegando que aquele mesmo conteúdo se encontra disponível nas redes sociais, tais como o Youtube, e até mesmo de forma mais dinâmica do que nas aulas da escola.

Para a prática docente nos dias atuais, a famosa educação bancária (ensino tradicional), na qual apenas o professor detém todo o conhecimento e o "deposita" na mente dos estudantes, não tem mais o poder e influência que tinha no século XX, visto que os alunos de hoje possuem enciclopédias digitais a todo momento em suas mãos (Silva; Leite \& Lins, 2019).

Além disso, Novais et al. (2021) apontam que o ensino tradicional não faz mais sentido nesse contexto de contínuo desenvolvimento tecnológico porque, as tecnologias ampliaram o acesso dos alunos a recursos ativos, os quais possibilitam ainda que o educando identifique as estratégias mais eficientes para o próprio aprendizado, das mais diversas áreas do conhecimento.

Com o intuito de alcançar esse público tão evoluído, o professor precisa atualizar sua forma de ensinar, usufruindo de recursos versáteis e valiosos como os dispositivos digitais e a internet em sala de aula, atuando como um facilitador e mediador do conhecimento, até porque, como dizia Paulo Freire (1996): "ensinar não é transferir conhecimento, mas criar possibilidades para sua própria produção ou a sua construção.”

Dentre esses recursos está a metodologia Webquest (WQ), criada e fundamentada por Bernie Dogde em 1995 como uma ferramenta em que guia o estudante na construção do conhecimento. A Web significa a internet e Quest os questionamentos que, de acordo com teoria de Piaget (1970), geram perturbações cognitivas no estudante até que ele assimile e acomode o novo conhecimento, entrando novamente no estado de equilibração.

De acordo com Vanz (2017), a WQ faz com que os estudantes se tornem ativos no processo de ensino e da aprendizagem, saindo de sua postura estagnada de simples receptor de informação, para ocupar um espaço de construtor de conhecimento, adquirindo autonomia para se desenvolver cognitivamente. Uma vez que, o professor atua como mediador da formação do conhecimento durante a aplicação de uma Webquest, é perceptível que uma WQ está baseada nos pilares da teoria construtivista. Através desta perspectiva metodológica, o educando tem a oportunidade de desenvolver inúmeras competências cognitivas, emocionais e sociais que o ensino tradicional não permitiria (Teixeira et al., 2020).

Segundo Santos e Barin (2015), a WQ é um exemplo de como empregar o potencial educativo dos recursos da internet dentro da perspectiva construtivista de Vygotsky, a qual valoriza o diálogo e a participação dos envolvidos e possui como alicerce a aprendizagem colaborativa para a construção do saber.

Santos (2015) afirma que, a Webquest se apresenta em um endereço de web, cujo conteúdo e construção são feitos pelo próprio professor. Sendo responsabilidade do docente realizar uma pesquisa e análise de todos os links, sites e outras 
fontes de pesquisa que serão consultados pelos alunos e incluídos na Webquest como referência para a pesquisa. Para auxiliar o professor na construção, Dodge (1995) classifica a WQ em dois tipos, que dependem exclusivamente do período em que a atividade será desenvolvida. Se esta durar de uma a três aulas, teremos uma Webquest curta, a partir do momento que durar de uma semana a dois meses teremos uma Webquest longa.

"Neste contexto, é importante destacar que a Webquest, faz a ponte entre as informações vindas da internet e a aquisição do pensamento crítico sobre o assunto abordado, de maneira que o professor é o orientador da atividade, norteando os alunos durante o estudo. Tendo por objetivo a resolução de problemas e o trabalho colaborativo dos estudantes, como também buscando potencializar o aprendizado de conteúdos científicos discutidos na atualidade" (Leite; Silva \& Lins, 2017, p. 121).

Vanz (2017) cita Silva (2006) afirmando que, a WQ auxilia o estudante a interpretar as informações recolhidas nos websites, buscando utilizar os conhecimentos científicos pesquisados para a compreensão e resolução da tarefa que deve estar, por sua vez, diretamente conectada a realidade vivenciada por esse público.

Para Rodrigues (2018), apesar da Webquest estar diretamente relacionada ao uso da internet, isso não significa que alguns dos recursos não possam ser livros impressos, ou acervos documentais que não encontramos disponíveis na web, pois a WQ é utilizada em prol do ensino, permitindo que o aluno trabalhe em grupo e construa o saber de forma colaborativa e cooperativa. Através desta ferramenta o aluno consegue chegar a um produto final, a partir de uma tarefa motivadora e por meio dos recursos disponibilizados pelo professor.

Diversos pesquisadores estão desenvolvendo Wequests adaptadas e/ou diferenciadas para sua área de conhecimento desejada, entre eles estão: Silva, Leite e Lins (2019), Jacinto, Rocha e Figueiredo (2018), Leite e Leão (2017), Vanz (2017) e Espuri, Passoni e Registro (2016). Os resultados de suas investigações apontam para uma aprendizagem facilitada na qual os alunos, movidos por esse novo tipo de atividade dentro de sala, se revelaram motivados e curiosos.

"O estudo da isomeria óptica ganha ênfase através do desastre da talidomida nos anos 60 , o qual foi resultado do uso de um medicamento que tem em sua estrutura química um carbono assimétrico (quiral), por conta disso apresentava dois isômeros ópticos que agiam simultaneamente, um reduzindo a sensação de enjoo e outro causando má formação dos fetos" (Leite; Silva \& Lins, 2019, p. 228).

A quiralidade dos carbonos, é o que normalmente caracteriza se a estrutura apresenta ou não isomeria óptica, mas para perceber se um carbono é quiral, é preciso observar a estrutura carbônica num campo tridimensional, ou seja, altura, profundidade e largura. Sulzbach (2017) cita Raupp (2010), dizendo que a maior dificuldade dos educandos, em isomeria óptica, se dá pela falta de compreensão dos problemas no nível tridimensional.

Ainda de acordo com Sulzbach (2017) este assunto tem sido tratado como irrelevante, complexo e desnecessário pelos estudantes, devido à falta de contextualização nas aulas de química. Sendo assim, como a isomeria óptica é de extrema importância na produção de fármacos e alimentos, faz-se necessário trazer metodologias diferenciadas que estimulem os estudantes a aprendizagem significativa deste assunto.

Diante deste contexto apresenta-se este trabalho, que tem por objetivo fazer uso da Webquest, com a intenção de expor como essa metodologia pode tornar o ensino e a aprendizagem de isomeria óptica mais significativo, de mostrar sua relevância para a construção do conhecimento autônomo, bem como trazer à tona a importância do uso dos dispositivos digitais para aproveitamento didático. 


\section{Metodologia}

O presente estudo trata-se de uma pesquisa de campo, de caráter exploratório e descritivo, que relaciona a Webquest como recurso didático na construção do conhecimento de isomeria óptica, por meio da apresentação de informações que possam servir de diretrizes para ações de transformação da realidade do ensino de química.

Os resultados são apresentados sobre forma quantitativa e qualitativa, a partir da coleta de informações de fontes primárias (entrevistas, questionários e pesquisa ação) e secundárias, (artigos científicos, livros, revistas). A planificação do estudo inclui, em primeiro lugar, o levantamento dos dados secundários e a revisão bibliográfica, para posterior contato com as fontes pessoais, a fim de promover a coleta de dados em campo.

O referido estudo contou com a participação de 34 estudantes, de uma escola pública localizada em Recife - PE, divididos em 5 grupos. Foi escolhida uma turma de $3^{\circ}$ ano do ensino médio por conta do conteúdo tratado na Webquest, que normalmente só é abordado para as turmas do último ano da Educação Básica. A pesquisa se deu em dois momentos, o primeiro foi destinado a criação da Webquest, e o segundo foi designado a aplicação da WQ e do questionário Pós-Webquest. A seguir, é detalhado cada uma destas etapas:

\subsection{Primeiro Momento}

Após a seleção do tema, iniciou-se a construção da Webquest através da plataforma virtual de criação de sites Wix, disponível em: https://xperimentandoquimica.wixsite.com/estereoquimica. A WQ criada é caracterizada como uma Webquest curta - que necessita de no máximo 3 aulas para ser concluída - em que os conteúdos e informações foram contextualizados com situações do cotidiano.

A Figura 1 apresenta o menu introdução da WQ, no qual se destaca uma questão associada ao conteúdo a ser estudado, com o objetivo de gerar questionamentos nos alunos. O cenário de fundo se relaciona a pergunta destacada, no que rolando a página há um texto que correlaciona qual o tema abordado (Isomeria Óptica), com exemplos visíveis no dia a dia dos estudantes, e responde à pergunta inicial. 
Figura 1 - Introdução do conteúdo a ser abordado na WQ.

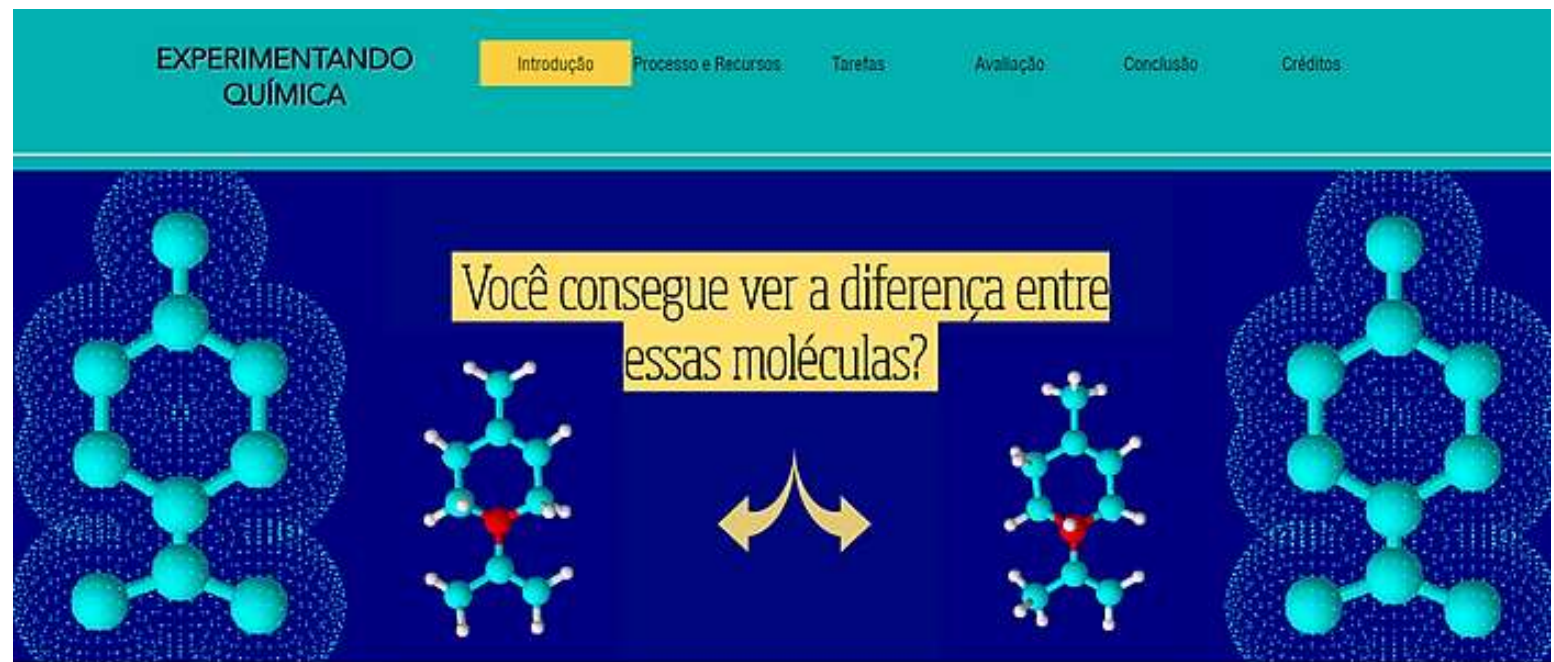

Por que você não pode calçar o sapato direito no pé esquerdo? Por que você não pode calçar a luva direita na mão esquerda? Porque măos, pess, luvas e sapatos tem formas direita e esquerda. Um objeto que tem forma direita e esquerda é chamado quiral. Um objeto quiral tem imagem especular nåo sobreponivel, em outras palavras, sua imagem não é o que parece ser.

Uma måo é quiral porque quando você olha para sua måo esquerda num espelho, năo é a måo esqueda que você vê, e sim a mão direita. Ao contrário, uma cadelra não é quiral porque ele aparece igual no espelho. Objetos năo quirais săo conhecidos como aquirais, e consequentemente tem imagem especurar sobreponivel, alguns exemplos sła: mesa, garfo e copo (BRUICE, 2006).

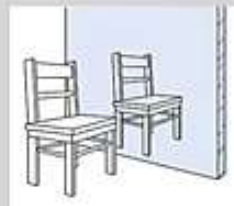

Cbjeto oputal

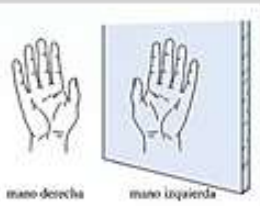

Osjets quird

Nosso conteúdo está totalmente ligado a quiralidade de substâncias orgânicas que săo isomeros. Estas substâncias conseguem rotacionar a luz polarizada (que so reflete em 1 direcalo) para direita ou esquerda. Embora, aparentemente elas sejam estruturas iguais, elas possuem propriedades diferentes. Um exemplo disso e a Ketamina que atua como um analgésico (S-Ketamina), porém possui um isỏmero optico que atua como um alucinogeno (R-Ketamina).
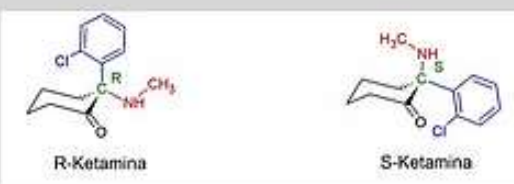

Fonte: Autores (2021).

$\mathrm{Na}$ Webquest, no menu tarefas, explicou-se que todos os grupos deveriam utilizar a cartolina disponibilizada pela professora para fazer um desenho em 3 dimensões (3D). Ao clicar no ícone seu grupo, os alunos eram direcionados a um pequeno resumo do assunto descrito na sua respectiva tarefa, dessa forma o que muda entre tarefa de um grupo do outro é o composto estudado. Esta WQ, atribuiu uma pontuação de 250 a 500 pontos a tarefa, e para a avaliação foi dada uma pontuação de até 500 pontos. No total, haveria 2 premiações, sendo assim, os dois grupos que tivessem a maior pontuação ganhariam o prêmio, que foi uma caixa de bis para cada equipe. A tarefa do grupo 1 foi desenhar a representação da luz natural passando por um polarímetro (Figura 2A), a tarefa do grupo 2, consistiu em desenhar as estruturas R (destrógera) e S (levógera) da molécula Talidomida (Figura 2B). 
Figura 2A - Tarefa grupo 1

\section{Sua missão:}

Olà grupo, sua missalo consiste em usar o cartaz disponibilizado para faze um desenho 30 e um pequeno resumo sobre: Luz Polarizada e Polarimetro.

Pode usar o formato que for mais interessante para vocts. Segue algumas inspiraçőes:
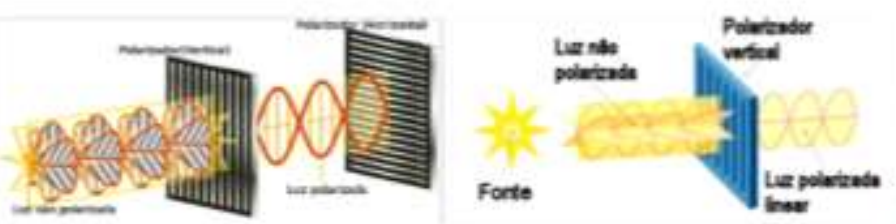

A partir da realizaça desta atividade. vocês receberdo urna pontuaçlo de $\mathbf{2 5 0}$ a $\mathbf{5 0 0}$ pontos Os cartazes mais criativos zanhardo as maiore: pontuaçes, entáo máos a obra!
Figura 2B - Tarefa grupo 2

\section{Sua missão:}

Olá grupa sua missào consiste em usar o cartaz dispon ibilizado para faze: um desenho 30 e um pequeno resumo sobre: Tallidomida e seus enantiómeros

Pode usar o formato que for mais interessante para vocks. Segue algumas inspiraçoes:

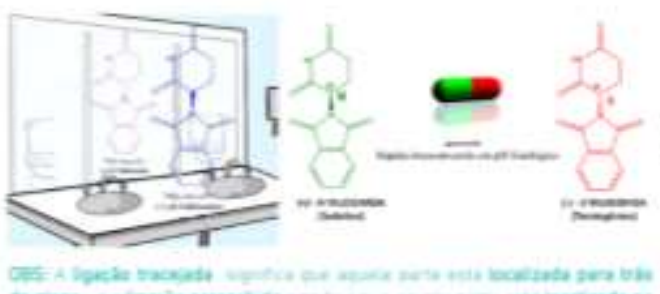

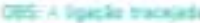

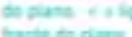

A partir da realizacalo desta atvidade, vocts receberao uma pontuacá de $\mathbf{2 5 0}$ a $\mathbf{5 0 0}$ pontos. Os cartazes mais criativos ganharao as maiores pontuaçbes, entalo mios a obra!

Fonte: Autores (2021).

A tarefa do grupo 3, consistiu em fazer um desenho 3D da Fenilalanina $\mathrm{R}$ e S (Figura 3A), a tarefa do grupo 4, constou em desenhar o Limoneno R e S, e a tarefa do grupo 5 foi desenhar as estruturas $\mathrm{R}$ e $\mathrm{S}$ da Carvona, todos em 3D (Figuras 3B e 3C).

Figura 3A - Tarefa grupo 3

\section{Sua missão:}

Ola grupo, sua missåo consiste em usar o cartaz disponibilizado para fazer um desenho 30 e um pequeno resumo sobre: Fenilalanina e os seus enantiomeros

Pode usar o formato que for mais interessante para vocés. Segue aigumas inspiraçoes:
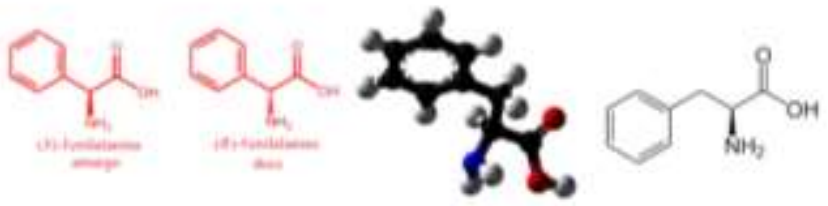

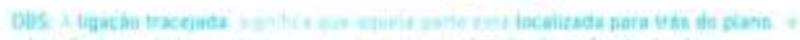

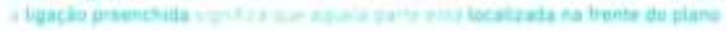

A partir da realizaçào desta atividade. vocés receberdo uma pontuaçà de 250 a $\mathbf{5 0 0}$ pontos. Os cartazes mais criativos ganhardo as maiores pontuaçồs, entào màos a obra!
Figura 3B - Tarefa grupo 4

\section{Sua missão:}

Olá grupo, sua missbo consiste em usar o cartaz disponibilizado para fazei um desenho 3D e um pequeno resumo sobre: Limoneno e seus enantiomeros

Pode usar o formato que for mais interessante para vocts. Segue aigumas inspiraçōes:
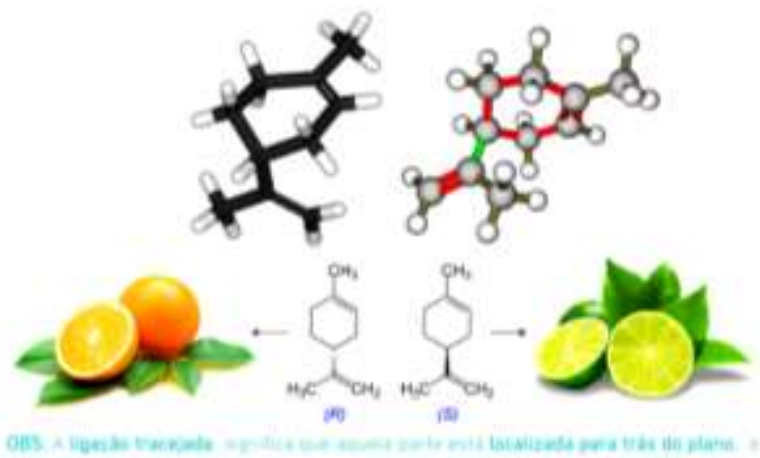

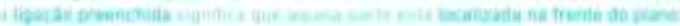

A partir da realizaçào desta atividade, vocês receberdo uma pontuaçào de 250 a 500 pontos. Os cartazes mais criativos ganhardo as maioret pontuaços, entao mios a obral 
Figura 3C - Tarefa grupo 5.

\section{Sua missã̃o:}

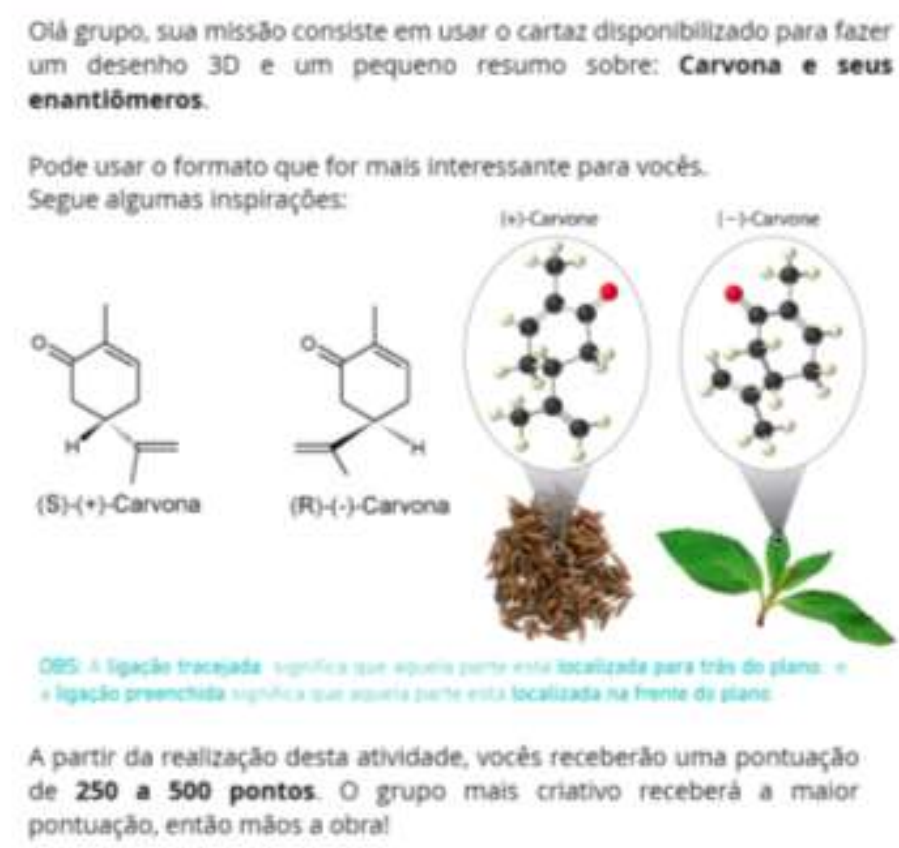

Fonte: Autores (2021).

A avaliação ocorreu pela apresentação do conteúdo dos cartazes de cada grupo, sendo assim, após a confecção dos cartazes os estudantes apresentaram para a turma o que eles aprenderam em suas pesquisas. No menu avaliação, explicou-se como seria construído o processo avaliativo. Neste, foi inserido um botão que direciona para o questionário, no qual estudantes avaliaram a sua experiência com a WQ.

No menu conclusão foi feito o fechamento do assunto e o agradecimento aos participantes. No menu créditos, se encontra os dados da autora, agradecimentos aos orientadores e os links dos sites, fotos e livros utilizados na construção da WQ.

Com a WQ pronta, iniciou-se o segundo momento da pesquisa pela aplicação da atividade na turma de $3^{\circ}$ ano do ensino médio.

\subsection{Segundo Momento}

Ao entrar na turma, foi apresentado o projeto, explicando que envolveria o uso do celular e da internet no decorrer da atividade, e foi dada uma breve explicação a respeito da Isomeria Óptica. Pediu-se que os alunos se dividissem em 5 grupos de 8 pessoas, e escreveu-se o site da WQ no quadro branco. Assim que os alunos acessaram o site, realizou-se a leitura da introdução por uma das alunas da classe, as dúvidas foram esclarecidas, e deu-se continuidade a WQ explicando como funcionaria as outras etapas, inclusive como funcionaria a tarefa de cada um, como acessar os links para pesquisa e como seria a avaliação. Com o intuito de auxiliar os estudantes nos desenhos, foi disponibilizado lápis e canetas coloridas pela professorapesquisadora. Os alunos levaram aproximadamente 2 aulas para confeccionarem os desenhos e fazerem os resumos da apresentação da equipe.

Após a apresentação as duas melhores equipes foram premiadas. Por fim, no menu Avaliação da WQ foi disponibilizado um link que direciona para um questionário, elaborado por meio da plataforma Google formulários, o qual 
cada aluno respondeu individualmente, consistindo-se em 6 questões tendo por objetivo averiguar a significância da metodologia WQ, para tornar as aulas de química mais atrativas, auxiliando na contextualização e facilitando o aprendizado.

\section{Resultados e Discussão}

Ao longo da atividade, pode-se descobrir vários talentos para o desenho, como também observar a construção de competências que fazem parte da Base Nacional Comum Curricular (BNCC, 2018), como: empatia e cooperação, a cultura digital, o domínio do conteúdo, pensamento crítico e criativo e a comunicação. Os estudantes participaram ativamente do processo, uns desenhando, uns pesquisando o conteúdo e outros escrevendo seus resumos. Muitos dos estudantes afirmaram, que não conseguiriam apresentar o trabalho por este ser seu primeiro contato com a isomeria óptica, alegando não saber nada sobre o tema. No entanto, com o fim da atividade, todos apresentaram seus respectivos temas muito bem. Diante disso, houve dois grupos que se destacaram ao ponto de receberam a premiação, os grupos 2 e 3.

A análise da primeira pergunta do questionário evidenciou que $94,1 \%$ dos alunos, avaliaram a isomeria óptica como importante para o cotidiano e 5,88\% avaliaram o conteúdo como não importante conforme a Figura 4.

Figura 4 - Isomeria óptica é importante para o cotidiano?

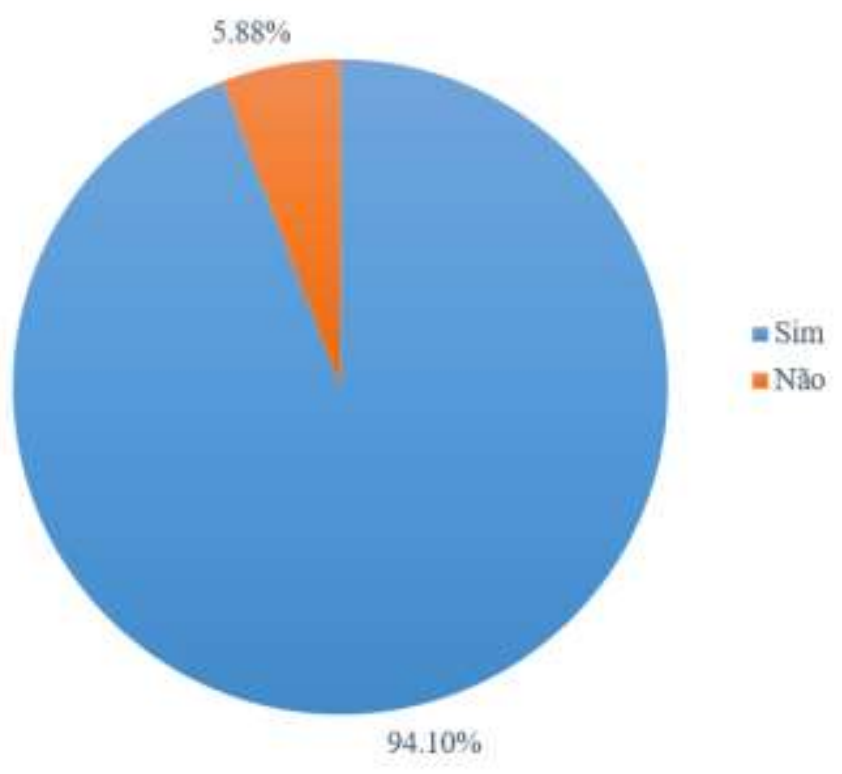

Fonte: Autores (2021).

Através dessas respostas testemunhou-se que grande parte dos estudantes realmente entenderam a importância do conteúdo para a vida deles, mudando sua concepção de que não existe importância nos assuntos da química.

A respeito da segunda pergunta, sobre importância da isomeria óptica para as indústrias farmacêutica e alimentícia, obteve-se algumas respostas como:

Aluno 1: "Para a farmacêutica é muito importante pois é possível saber os efeitos dos fármacos no organismo humano, pois se uma substância for quiral ela pode possuir um enantiômero com atividade farmacológica prejudicial"

Aluno 2: "Para saber os efeitos causados pela substância e produzir remédios e alimentos com função de melhorar ou ajudar algo específico de acordo com a função de cada parte da substância"

Aluno 3: "Porque algumas substâncias podem modificar os sabores de alimentos e mudar a função dos remédios" 
Aluno 4: "Para estudar o comportamento das moléculas e elaborar remédios e alimentos com um conhecimento melhor de seus efeitos"

Aluno 5: "Para não usar uma substância que vá prejudicar seus consumidores"

Com estas respostas, também foi confirmado que houve aprendizado de isomeria óptica, pois os estudantes deram boas justificativas para a importância da isomeria óptica nas indústrias.

De acordo com a Figura 5B pode-se constatar, em resposta à pergunta três, que 55,8\% dos alunos afirmaram ter aprendido o conteúdo, 38,2\% afirmaram que não houve aprendizado e 5,88\% afirmara ter aprendido pouco.

Observou-se na aplicação, que muitos dos alunos da turma, estavam relutantes em se "abrir" para esse tipo de aula, não interagindo totalmente com o grupo e nem participando ativamente durante o processo. No entanto, mais de $50 \%$ da turma, confirmou que aprendeu com a metodologia WQ.

Contempla-se também através da Figura 5A, que muitos dos alunos, por influência do ensino tradicional, não se sentem familiarizados com esse tipo de recurso didático, passando até a questionar da sua aprendizagem a partir desta metodologia.

Na Figura 5B que trata a pergunta 4, está representado o quanto essa atividade foi bem aceita pelos alunos. 91,2\% dos alunos ficaram satisfeitos com a atividade. Isto demonstrou, que embora muitos educandos ainda estejam condicionados e acomodados no modelo de ensino tradicional, eles estão dispostos ao uso de novas ferramentas didáticas em sala de aula.

Figura 5A - Como você avalia seu aprendizado pela WQ?

Figura 5B - Você gostou desse tipo de aula?
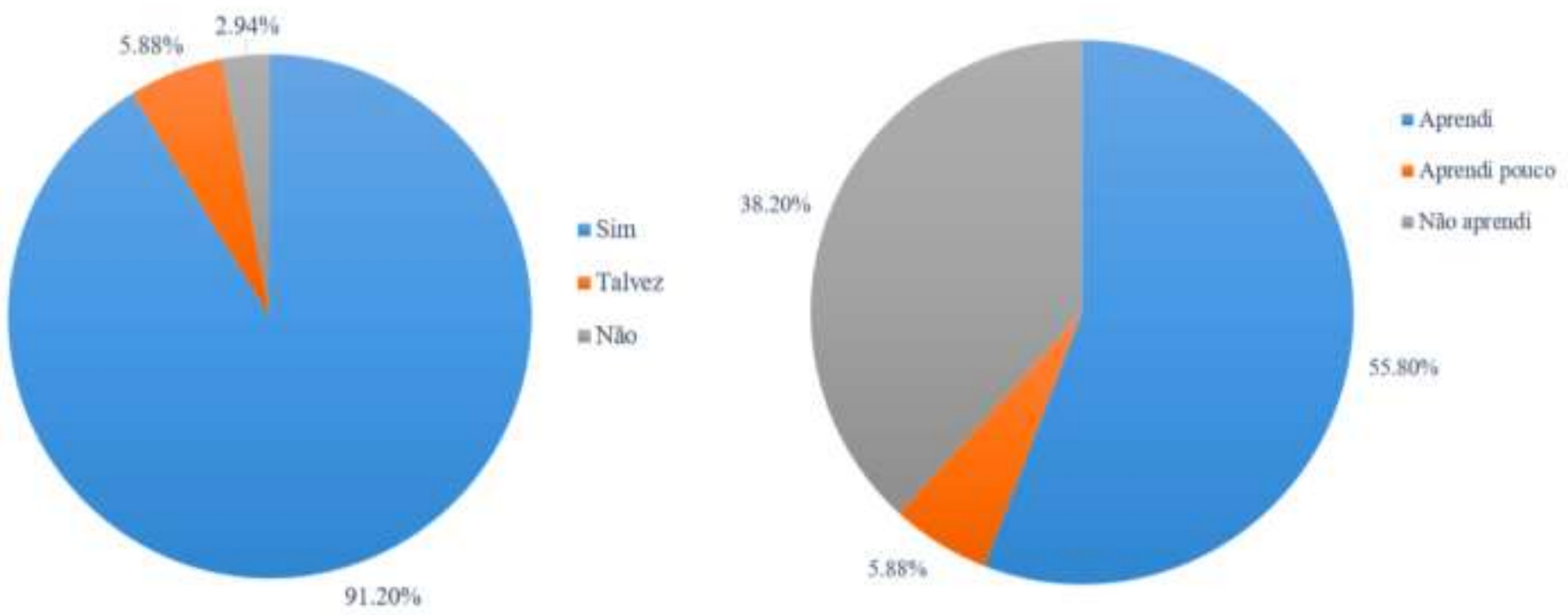

Fonte: Autores (2021).

Ainda foi perguntado, qual parte da WQ que os alunos mais gostaram, questão 5, apenas um estudante disse que não gostou de nada. Em contrapartida, obteve-se respostas extremamente positivas de outros alunos:

Aluno 1: "Das apresentações e explicações dos grupos"

Aluno 2: "De desenhar e de saber que o limão e a laranja são tão parecidos na fórmula"

Aluno 3: "Gostei mais de ter sido uma aula diferente e interativa"

Aluno 4: "Foi uma aula divertida e diferenciada"

Aluno 5: "Poder usar a internet como auxílio" 
Aluno 6: "Da parte do trabalho em equipe, pois quem não sabe do assunto pode se juntar com as pessoas que sabem, e assim ajudar o próximo."

Aluno 7: "Do conteúdo em si"

Aluno 8: "De trabalhar a matéria de química de outra forma"

Aluno 9: "Gostei de aprender mais sobre o assunto e descobrir sua importância na vida das pessoas"

Aluno 10: "O jeito como a aula foi feita, através de pesquisas no celular e com desenhos"

Essas respostas mostram definitivamente, que os estudantes estão aptos em aceitar novos recursos didáticos que os desafiem, instiguem sua curiosidade, criatividade e seu pensamento crítico. Confirmando a eficiência da metodologia WQ para o ensino e aprendizagem de conceitos.

Quanto a pergunta 6: se os estudantes tinham alguma sugestão, nenhum sugeriu alguma alteração ou adição. De um modo geral, pôde-se constatar que num primeiro momento, os estudantes tiveram um certo estranhamento com este tipo de atividade, porém gostaram do conteúdo e da forma que ele foi abordado, até sugerindo que ocorressem mais aulas como esta.

\section{Conclusão}

O uso da metodologia Webquest têm sido um recurso didático de grande impacto no ambiente escolar, principalmente para o ensino de química. A diversificação do ensino por meio desta, está ampliando e reconfigurando ideias já existentes na estrutura mental dos estudantes, os tornando capazes de relacionar e acessar novos conteúdos.

Com os dados obtidos nesta pesquisa, observa-se a necessidade de uma mudança na prática pedagógica dos professores, para que haja melhorias na compreensão dos conceitos químicos e construção da aprendizagem dos estudantes. Tendo em vista que os educandos se mostraram muito interessados em discutir e adotar novos desafios na utilização de novas metodologias de ensino, evitando as aulas que sigam o modelo tradicional.

Desta forma, a partir dos resultados obtidos, a Webquest aplicada foi bem aceita pelos alunos, os quais demonstraram interesse em realizar a tarefa designada de acordo com sua equipe, permitindo um maior contato com os conhecimentos de Isomeria Óptica relacionados com o cotidiano. Alguns dos estudantes estão tão acomodados com o ensino tradicional, que foram bastante resistentes à metodologia, o que trouxe uma reflexão a respeito da falta do uso das TICs como recurso didático.

É importante destacar que o objetivo deste estudo, além de promover a compreensão de Isomeria Óptica, também foi esclarecer a presença deste assunto em várias situações do cotidiano dos estudantes, o relacionando com diversas problemáticas que surgem da vida em sociedade.

Por fim, a partir da aplicação da metodologia WQ, percebeu-se que houve um despertar no interesse dos estudantes pelo aprendizado da química, como também uma maior participação do processo de ensino-aprendizagem.

\section{Agradecimentos}

Agradecemos a Universidade Católica de Pernambuco e a Capes pela concessão de bolsa de Residência Pedagógica.

\section{Referências}

Brasil. Ministério da Educação. MEC. (2018). Base Nacional Comum Curricular. Educação é a Base. Ensino Médio.

Dodge, B. (1995). WebQuests: A Technique for Internet-based learning. The Distance Educator. 1, 2, 10-13.

Espuri, P. H., Passoni, T. P., \& Registro, E. S. R. (2016). Shakespeare ao Quadrado na Webquest: Uma Proposta de Reflexão a partir do gênero HQ. The Especialist, 37(1).

Freire, P. (1996). Pedagogia da Autonomia: saberes necessários à prática educativa. Paz e Terra. 
Research, Society and Development, v. 10, n. 8, e31810817346, 2021

(CC BY 4.0) | ISSN 2525-3409 | DOI: http://dx.doi.org/10.33448/rsd-v10i8.17346

Jacinto, S., Rocha, Z. D. F. D. C., \& Figueiredo, M. C. (2018). Usabilidade de uma Webquest para o ensino de Propriedades Coligativas. Revista de Educação, Ciências e Matemática, 8(1).

Leite, B. S., \& Leão, M. C. (2017). Considerações sobre webquests e flexquests no ensino de química. Enseñanza de las ciencias: Revista de investigación y experiencias didácticas, Extra, 1585-90.

Leite, L. F. C. C., Silva, A. L. \& Lins, R. C. (2019). Adaptação de uma WebQuest em uma FlexQuest para o ensino de Química Inorgânica: Ácidos e Bases e Uso Doméstico. In: S. A. S. Monteiro (Org.). Pensando as Licenciaturas. (Vol. 1, Cap. 14, pp.118-129). Atena.

Leite, L. F. C. C., Silva, A. L., \& Lins, R. (2019). Uma Webquest para facilitar o ensino de isomeria óptica. In: M. B. Justus (Org.) Formação de Professores e a Condição do Trabalho Docente 2. (Vol. 2, Cap. 22, pp. 223-229). Atena.

De Novais, M. A. B., da Silva, E. S., Costa, M. K. R., de Amorim, P. A., Machado, F. L. M., Machado, A. M. M. R., Moura, J. S., de Paiva, C. R. B., Martins, I. S., Paulino, F. G. O., de Araújo, M. N., de Medeiros,J. L. \& André, A. S. (2021). Metodologias ativas no processo de ensino e de aprendizagem: Alternativas didáticas emergentes. Research, Society and Development, 10(4).

Palfrey, J. \& Gasser, U. (2011). Nascidos na era digital: entendendo a primeira geração de nativos digitais. Artmed

Piaget, J. (1975). O nascimento da inteligência na criança. Zahar.

Raupp, D. J. (2010). Um estudo de caso sobre a compreensão de conceitos químicos mediante a visualização de representações computacionais $3 D$ utilizando o referencial de campos conceituais. (Dissertação de Mestrado). Universidade Luterana do Brasil, Canoas, RS, Brasil.

Rodrigues, A. J. W. (2018). Ensino de língua portuguesa por meio da metodologia WebQuest no ensino regular: uma proposta didática que inclui o mundo virtual dos aprendizes na sala de aula. (Dissertação de Mestrado). Universidade Federal do Pampa, Bagé, RS, Brasil.

Santos, T. R. (2015). A metodologia WebQuest na problematização dos conceitos Químicos como estratégia para promover a aprendizagem significativa. (Dissertação de Mestrado). Universidade Federal de Santa Maria, RS, Brasil.

Santos, T. R. \& Barin, C. S. (2015). WebQuest como atividade motivadora para a aprendizagem de Química. Revista Tecnologias na Educação, 12(12).

da Silva, A. L. (2021) Experimentando Química - Estereoquimica. https://xperimentandoquimica.wixsite.com/estereoquimica.

da Silva, A. L., Leite, L. F. C. C. \& Lins, R. C. (2019). Uma Webquest para auxiliar o Ensino de Química Inorgânica. Hipertextus Revista Digital, 20(4).

Silva, M. B. (2006). A geometria espacial no ensino médio a partir da atividade WebQuest: análise de uma experiência. (Dissertação de Mestrado) Instituto de Física, Pontifícia Universidade Católica de São Paulo, SP, Brasil.

Souza, K. R. A. P. (2015). Elaboração e aplicação de uma unidade de ensino potencialmente significativa para o ensino-aprendizagem de isomeria. (Dissertação de Mestrado). Instituto de Química, Universidade Federal Fluminense, RJ, Brasil.

Sulzbach, A. C. (2017). O ensino de isomeria óptica por meio de atividades experimentais. (Dissertação de Mestrado). Centro de Ciências Naturais e Exatas, Universidade Federal de Santa Maria, RS, Brasil.

Teixeira, Y. N., Soares, C. A. B., de Almeida, R. P., Campos, L. M. M. R., de Souza, A. R., Pinheiro, A. A. G \& de Queiroz, Z. F. (2020). Metodologias ativas em tempos de aulas remotas: compreendendo as diferenças entre o ensino público e privado em cidades do interior do Ceará. Research, Society and Development, 9(12).

Vanz, L. (2017). A utilização de WebQuest para o ensino de radioatividade. (Dissertação de Mestrado). Instituto de Ciências Exatas e Geociências, Universidade de Passo Fundo, RS, Brasil. 